\title{
Amor e desafios: um estudo dos posicionamentos e avaliações de professores de inglês como língua estrangeira diante de sua profissão.
}

\author{
Suzana de Carvalho Barroso Azevedo \\ CEFET/RJ, PUC-Rio
}

\begin{abstract}
Resumo
Este artigo tem como foco o discurso de professores de inglês como língua estrangeira, buscando compreender como essas pessoas se posicionam discursivamente em relação ao magistério e quais avaliações sobre a profissão podem ser identificadas em seus discursos. $\mathrm{O}$ aporte teórico utilizado baseia-se nos princípios da Linguística Sistêmico-Funcional (HALLIDAY, 1994; HALLIDAY \& MATTHIESSEN, 2004) e do Sistema da Avaliatividade (MARTIN, 2001; MARTIN \& WHITE, 2005), perspectivas que concebem a linguagem como orientada para o uso e dotada de recursos que veiculam posicionamentos e atitudes frente aos fenômenos do mundo. Sendo assim, foram analisados textos escritos por professores de língua inglesa que atuam em diferentes contextos e níveis. As análises indicam que os professores assumem atitudes de afeto diante da atividade docente e avaliam negativamente o atual contexto educacional brasileiro.

Palavras-Chave: Discurso, Professores de Inglês, Linguística SistêmicoFuncional, Sistema da Avaliatividade
\end{abstract}

\begin{abstract}
The present article focuses on the discourse of teachers of English as a foreign language. The aim is to understand how these teachers take a discursive position in relation to teaching and what evaluations about their professions can be identified in their discourses. The theoretical framework is based on the principles of Systemic Functional-Linguistics (HALLIDAY, 1994; HALLIDAY \& MATTHIESSEN, 2004) and the Appraisal System (MARTIN, 2001; MARTIN \& WHITE, 2005). Such perspectives conceive language as a use-oriented system which has resources to express attitude in relation to world phenomena. Therefore, texts written by teachers of English as a foreign language who work in different contexts and levels were analyzed. The analyses indicate that teachers assume an affect attitude towards their teaching practices, but they also negatively evaluate the current Brazilian educational context.

Keywords: Discourse, English teachers, Systemic Functional Linguistics, Appraisal System
\end{abstract}




\section{INTRODUÇÃO}

O estudo das percepções do professor sobre sua prática profissional constitui-se como uma das formas de entendimento não só da atividade docente em si, com suas peculiaridades e desafios, como também de questões relativas ao cenário educacional brasileiro. Sendo assim, ouvir tais profissionais consiste em buscar significados no discurso daqueles que de fato vivenciam as práticas sociais no contexto do ensino e aprendizagem.

Esta proposta alinha-se à tendência mais recente da Linguística Aplicada (LA), área que busca examinar questões em que a linguagem tem papel central com o auxílio de diversas disciplinas, de forma conjugada, como a linguística, a psicologia e a sociologia, por exemplo (MOITA LOPES, 2006). Nesta orientação mais atual da LA, é necessário não só teorizar sobre a vida social, mas também compreendê-la a partir de um novo olhar, considerando, sobretudo, a perspectiva das vozes marginais, historicamente silenciadas por correntes sancionadas a ditar padrões e instituir formas legítimas de viver (Ibid.).

Entendo que o professor fala justamente desse lugar de desprestígio social onde suas percepções foram sendo, gradativamente, apagadas por profissionais e especialistas que muitas vezes não vivem a experiência diária do magistério. Destituídos de seu direito de opinar e, sobretudo, deliberar sobre as questões educacionais, o professor passa a ser visto como um mero técnico executor de procedimentos metodológicos.

O professor de inglês como língua estrangeira, público participante desta pesquisa, sente-se, em geral, identificado com as questões mencionadas. Primeiramente, pela recorrente desvalorização de sua disciplina na educação básica, notória tanto na quantidade de tempos semanais a ela reservados como também nas pressões geralmente impostas nas práticas de avaliação e reprovação. Além disso, o professor de inglês como língua estrangeira está sujeito a uma gama de técnicas e métodos de ensino que lhes são impostos nos vários contextos educacionais onde atua ao longo de sua carreira e, tais metodologias normalmente não estão abertas a questionamentos e negociações.

Diante disso, corroboro a perspectiva contemporânea da LA em contemplar as vozes habitualmente excluídas do debate, e acrescento a contribuição de Giroux (1997, p. 157) de enxergar os professores como "intelectuais transformadores", isto é, profissionais capazes de teorizar, criticar e refletir sobre as práticas educacionais a que estão submetidos. Dessa maneira, a voz desse profissional deve ser o principal 
mecanismo na elaboração de um panorama da vida em sala de aula e, consequentemente, do cenário educacional do país. Por esse motivo, esta pesquisa enfoca o discurso do professor de inglês como língua estrangeira, tendo por objetivo entender como esses profissionais se posicionam discursivamente em relação ao magistério e quais avaliações sobre sua profissão estão presentes em seu discurso.

Além desta introdução, o artigo em tela está dividido em cinco seções. Inicialmente, faço uma exposição sobre o estudo do discurso em contextos pedagógicos, campo central em que se desenvolve esta pesquisa. Em seguida, há uma revisão da Linguística Sistêmico Funcional (LSF) (HALLIDAY, 1994; HALLIDAY \& MATTHIESSEN, 2004), teoria que embasa a visão de linguagem presente neste estudo, e do Sistema da Avaliatividade (MARTIN, 2001; MARTIN \& WHITE, 2005), cujas subcategorias informam a análise de dados. O item Metodologia contém uma descrição do contexto de pesquisa, participantes, geração de dados e procedimentos de análise. A seção de Análise de Dados está dividida em dois eixos temáticos de acordo com os assuntos levantados pelos participantes. O artigo termina com a parte intitulada "Considerações Finais", onde proponho uma retomada aos pontos mais importantes até então apresentados e aponto as contribuições da pesquisa.

\section{O ESTUDO DO DISCURSO EM CONTEXTOS PEDAGÓGICOS}

A linguagem é constitutiva da vida social na medida em que as pessoas fazem sentido e se (re) constroem e constroem aos outros por meio do discurso. O discurso é uma forma de ação no mundo, isto é, enquanto sujeitos sociais que somos estamos constantemente fazendo coisas por meio da linguagem e (re) significado o mundo através dos discursos nos quais nos engajamos.

Além de construir a vida social, a linguagem é, também, localizada no tempo e espaço e por isso o discurso se co-constrói no contexto situacional em que se desenrola. Para Moita Lopes (2003, p. 22), “todo ato discursivo se dirige a alguém e toda prática discursiva é situada no mundo sócio-histórico e cultural em que ocorre, isto é, não ocorre em um vácuo social".

A linguagem tem a característica de estabelecer trocas e negociações de significados. De acordo com Bakhtin (1992), a perspectiva de linguagem que desconsidera o papel também ativo do ouvinte é errônea. O autor explica que a 
responsabilidade pela comunicação verbal sempre foi atribuída ao locutor como se estivesse sozinho no processo interacional, minimizando, desta forma, o papel do interlocutor, relegado a uma posição de ouvinte passivo que apenas recebe a informação pronta e a compreende. No entanto, Bakhtin (2000) considera essa visão uma distorção do complexo processo de comunicação verbal e advoga que o ouvinte não é um mero receptor inerte de significados, pelo contrário, ele responde ativamente aos enunciados propostos pelo tradicional locutor e adota atitudes de concordância, discordância, complementação, adaptação, execução, etc., tornado-se, portanto, um locutor.

Para Vygostsky, o discurso é uma forma social de pensar onde os indivíduos trocam informações, constroem idéias e disponibilizam formas alternativas de ver o mundo (MERCER, 1994). Sendo assim, os significados são "compreendidos como resultado dos processos sociointeracionais em que nos engajamos no dia a dia no esforço conjunto de entender a vida à nossa volta" (MOITA LOPES, 2003, p. 23)

Posto que a linguagem é uma forma de ação no mundo contextualmente situada e dirigida a alguém, faz-se necessário pensar sobre seu papel no círculo educacional. $\mathrm{O}$ processo de ensino e aprendizagem é mediado pela linguagem e esta é vista como "um meio de compartilhar conhecimento e potencialmente, transformar o entendimento" (MERCER, 1994, p. 95). Assumindo uma perspectiva dialógica do ensino e da aprendizagem, Wells (1999) revisita Bakhtin e Vygostsky e destaca a importância de se perceber a atividade em sala de aula como uma via de mão dupla, ou seja, um processo situado em um espaço permeado por vários discursos onde o conhecimento é construído por todas as partes.

Essa visão de linguagem e de sua relação com o processo de ensino e aprendizagem constitui argumentos bastante sólidos para defender a necessidade da pesquisa em contextos pedagógicos. Stubbs (1992) relaciona vários motivos para o estudo da linguagem em sala de aula como, por exemplo, a crença de que o entendimento do ensino e aprendizagem muito depende da observação de professores e alunos. A pesquisa em sala de aula também é descrita por Allwright \& Bailey (1991) que afirmam ser esta a forma de investigar o que de fato acontece nesse ambiente. Os autores explicam que a pesquisa em sala de aula pode ser feita simplesmente por meio da observação, coleta de dados e análise.

Compactuo com o argumento da necessidade da pesquisa das interações ocorridas em sala de aula; no entanto, nesse trabalho, gostaria de chamar a atenção para 
um outro tipo de foco para o discurso em contextos pedagógicos que é o estudo do discurso do professor. Tal discurso está carregado de crenças e concepções acerca de questões educacionais, podendo a sua observação ser um instrumento de reflexão e entendimento desses valores. A partir da compreensão das crenças e idéias que subjazem o discurso do professor, muitos entendimentos sobre o comportamento, identidades, anseios e expectativas desses profissionais poderiam ser gerados.

O aspecto positivo da geração dos entendimentos em questão se dá, em princípio, para o próprio professor que além de ter a oportunidade de refletir sobre sua prática, reafirmando-a e/ou resignificando-a, pode também identificar crenças enraizadas no seu discurso que, de alguma forma, se refletem na sua atividade docente. Além disso, dar voz ao professor e estimulá-lo a questionar, relatar e refletir acerca de sua profissão é, acima de tudo, uma forma de fazer valer a cidadania e dar o direito de falar a quem de fato vivencia a experiência diária do magistério. Por fim, a partir da compreensão gerada pelo estudo do discurso do professor, discussões acerca de possíveis modificações no sistema educacional, na formação docente e nas políticas públicas poderiam ser fomentadas.

\section{LSF E SISTEMA DA AVALIATIVIDADE}

A Linguística Sistêmico-Funcional (HALLIDAY, 1994; HALLIDAY \& MATTHIESSEN, 2004) é uma teoria que considera a linguagem como uma rede de possibilidades na qual os falantes fazem escolhas para expressar funções determinadas. Um dos precursores da LSF foi o lingüista Britânico Michael Alexander Kirkwood Halliday, autor da obra mais referenciada nos estudos sistêmico-funcionais: $A n$ Introduction to Functional Grammar.

A perspectiva funcionalista para estudos lingüísticos entende a língua como um sistema orientado para o uso e que evolui para satisfazer as necessidades dos usuários que dela se apropriam para veicular significados. Para a LSF não existe língua desconectada do uso, ou seja, a linguagem é social e só ocorre se estiver imbricada na sociedade. A gramática, por sua vez, é um sistema naturalmente relacionado ao significado que realiza padrões semânticos utilizados pelos falantes para expressar funções na vida social. 
Sendo uma teoria direcionada pelo uso, a LSF toma o texto como base de análise. Para Halliday (1994), o texto é uma unidade semântica realizada através da lexicogramática ou sistema de fraseados, que são a concretização das escolhas dos falantes/escritores no sistema. Dessa maneira, a linguagem tem potencial de significados e se constitui em um sistema onde os usuários selecionam as opções mais apropriadas para expressar os sentidos que desejam. Ao mesmo tempo, a língua realiza as escolhas dos usuários, instanciando o sistema por meio do tex to (GOUVEIA, 2009).

Tendo em vista que "conforme as necessidades dos falantes em contextos específicos são as escolhas no que tange às formas que expressam os significados desejados" (BARBARA \& MACEDO, 2009, p. 91), é necessário destacar a noção de contexto para os estudos funcionais. O contexto é um outro texto que rodeia o texto principal com vistas a instaurar uma relação este último e a situação geral em que ele se desenrola. Halliday (1994) valeu-se dos estudos de Malinowski (1923) para estabelecer as noções de Contexto de Cultura e Contexto de Situação, delimitadas a seguir.

O Contexto de Cultura equivale a um grupo de procedimentos que as culturas instituem como uma forma de agir (EGGINS, 2004). Trata-se de "todo o histórico cultural por trás dos participantes e das práticas nas quais eles se engajam, determinando significados práticos ou rituais naquela cultura" (HALLIDAY \& HASAN, 1989). Já o Contexto de Situação refere-se ao "ambiente do texto" (Ibid.), local mais imediato onde este se desenvolve. O Contexto de Situação compreende três variáveis: modo, que diz respeito ao papel da linguagem naquela interação; campo, que configura o assunto do texto, aquilo sobre o que se fala e relações, que se refere às relações estabelecidas entre os participantes. Os elementos do Contexto de Situação modo, campo e relações acomodam, respectivamente, as três funções ou significados identificados por Halliday (1994) os quais a linguagem realiza: Textual, Ideacional e Interpessoal. Esses significados são denominados pelo autor de Metafunções da linguagem.

A Metafunção Textual refere-se à capacidade da linguagem de organizar a mensagem em um significado que seja reconhecível para o interlocutor. A estrutura temática constrói uma rede de relações lógicas para dar origem ao significado. Para tanto, um elemento é enunciado como Tema e articula-se com o restante da mensagem denominado Rema. O Tema é, portanto, o ponto de partida da mensagem, a base a partir da qual o enunciado se constrói. Quando o locutor decide tematizar um determinado 
item colocando-o em primeiro lugar no enunciado, ele imprime nesse elemento uma importância, outorgando-lhe um lugar de destaque dentro da mensagem.

A Metafunção Ideacional refere-se à característica da linguagem de possibilitar a representação do mundo, a transmissão e construção de ideias. Na lexicogramática, a Transitividade $^{1}$ é o sistema semântico responsável que realiza essa Metafunção. De acordo com esse sistema, a experiência humana constitui-se em um fluxo de acontecimentos materializados por meio de Processos, cuja representação na gramática tradicional ocorre, sobretudo, por verbos. A Transitividade engloba também Participantes que estão envolvidos de alguma forma no desdobramento dos Processos e Circunstâncias de tempo, modo e espaço atreladas ao Processo.

Em se tratando da Metafunção Interpessoal, podemos dizer que ela está relacionada com a característica da linguagem de ser utilizada para estabelecer trocas entre locutores e interlocutores de uma interação. A realização gramatical dessa Metafunção verifica-se por meio do Modo Oracional, composição Sujeito + Finito, onde, na terminologia funcional, o primeiro é o responsável pela validade da proposição enquanto que o segundo denota tempo e polaridade. Segundo Halliday e Matthiessen (2004) em todo evento interacional, o locutor (falante/escritor) elege um papel discursivo específico para si, atribuindo ao interlocutor (ouvinte/leitor) uma função complementar a qual deseja que este último assuma.

A Metafunção Interpessoal é especialmente relevante para a análise realizada nesta pesquisa, pois é a partir dela que se desenvolve o Sistema da Avaliatividade, que passo a descrever agora. Tal sistema é uma ramificação da Metafunção Interpessoal e contribuirá para que verifiquemos o posicionamento e as avaliações presentes no discurso de professores participantes.

O Sistema da Avaliatividade vem sendo desenvolvido desde os anos 90 por um grupo de pesquisadores do departamento de linguística da Universidade de Sidney, entre os quais se destaca o professor James Martin. O sistema, considerado uma extensão da LSF, busca incorporar a semântica da avaliação às análises linguísticas objetivando estudar como os interlocutores se sentem, os julgamentos realizados e o valor atribuído aos vários fenômenos com os quais se deparam (MARTIN, 2000).

\footnotetext{
${ }^{1}$ Os termos da gramática sistêmico-funcional em português foram retirados da lista aprovada pelas equipes de investigação da FLUL, do projeto DIRECT da PUC-SP e por outros pesquisadores da LSF.
} 
Sendo assim, o sistema em questão estuda a atitude dos usuários da língua em face aos fenômenos da nossa experiência, tendo como foco os recursos utilizados pelos falantes/escritores para avaliá-los e se posicionar ideologicamente em seu discurso. A fim de analisar tais recursos nas trocas entre participantes da interação, Martin (2000) sugere sistemas lexicalmente orientados que funcionem juntamente com os modelos de base gramatical formulados pela LSF. O pensamento de Bakhtin (1988a, p. 95) respalda esta orientação:

(...) não são palavras o que pronunciamos ou escutamos, mas verdades ou mentiras, coisas boas ou más, importantes ou triviais, agradáveis ou desagradáveis, etc... A palavra está sempre carregada de um conteúdo ou de um sentido ideológico ou vivencial.

Foram propostas, portanto, três subsistemas que correspondem aos tipos de significados utilizados pelos interactantes para colocarem-se em relação ao mundo, a saber: Atitude, Engajamento e Gradação. Atitude refere-se aos recursos utilizados pelos falantes para manifestar emoções, julgar condutas e avaliar objetos e fenômenos. Engajamento diz respeito aos mecanismos utilizados para expressar, negociar e naturalizar posicionamentos subjetivos e ideológicos, estando, portanto, relacionado ao potencial retórico de textos. Gradação são os recursos através dos quais participantes de uma interação graduam o impacto, força ou volume dos enunciados que proferem (WHITE, 2001). Na pesquisa aqui relatada, apenas o sistema de Atitude será considerado para fins de análise, já que ele contempla os objetivos do estudo de investigar os posicionamentos e avaliações feitas por professores de inglês como língua estrangeira no âmbito de sua profissão.

O sistema da Atitude divide-se nas categorias AFETO, JULGAMENTO e APRECIAÇÃO, concernentes a atitudes emocionais, éticas e estéticas respectivamente (WHITE, 2001). As três subdivisões supracitadas possuem as seguintes propriedades: a) denotar status positivos ou negativos; 2) figurar nos enunciados de maneira implícita ou explícita e 3) apontar posicionamentos atitudinais por meio de palavras individuais, orações ou interação de vários elementos dos enunciados.

AFETO está relacionado a reações e inclinações emocionais e pode ser realizado

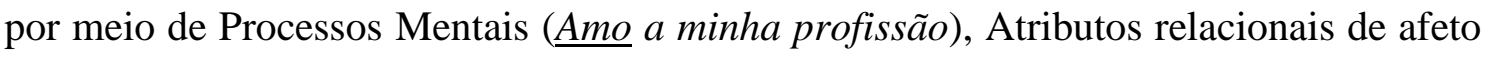
(O professor deve ser apaixonado pelo que faz) ou substantivos (A característica que faz a diferença é o amor pela profissão). Portanto, o AFETO é o recurso por meio do 
qual interlocutores demonstram como fenômenos os afetam emocionalmente. Outrossim, ao fazer uma avaliação com teor afetivo, o locutor convida seu interlocutor a compartilhar consigo o mesmo tipo de envolvimento com o fenômeno. Dependendo da resposta de aceitação ou rejeição a esse "convite", pode ser estabelecida a solidariedade entre as partes ou o desacordo ideológico (WHITE, 2001)

JULGAMENTO é a categoria do Sistema da Avaliatividade que visa avaliar o comportamento humano com base em normas institucionalizadas. Martin \& White (2005) sugerem uma divisão do subsistema JULGAMENTO nos grupos Sanção Social e Estima Social. No primeiro caso, o JULGAMENTO tem consequências legais ou morais e os comportamentos são alvos de elogios ou condenação. No segundo tipo, o JULGAMENTO não acarreta em sanções legais ou morais, mas envolvem julgamentos por meio dos quais os indivíduos são alvos de admiração ou crítica dentro de uma comunidade. Cumpre ressaltar que o código de conduta esperado de indivíduos é culturalmente orientado, de maneira que todas as análises com essa categoria serão mais notadamente sócio-historicamente localizadas em um contexto de cultura.

APRECIAÇÃO refere-se à avaliação de fenômenos, objetos e processos. A APRECIAÇÃO é estruturada em três subtipos: reação, composição e valor. Reação diz respeito à forma como um texto ou objeto atinge o leitor/ouvinte emocionalmente, tanto através do impacto causado (Isto me tocou?) quanto de sua qualidade (Eu gostei disso?). A Composição diz respeito à avaliação de algo conforme sua proporcionalidade ou equilíbrio (Isto estava coeso?) ou detalhe ou complexidade (Isto foi difícil de acompanhar?). Por fim, o Valor é a importância social conferida aos processos ou produtos (Isto valeu a pena?) (MARTIN, 2000).

Tanto a LSF quanto a variável da Atitude do Sistema da Avaliatividade são consoantes com a proposta de estudo desenvolvida neste artigo. A LSF e a visão de linguagem a ela subjacente leva em consideração a língua em uso que deve ser entendida associada aos fatores contextuais, interacionais e sociais. O Sistema de Avaliatividade, por sua vez, dispõe das categorias de análise AFETO, JULGAMENTO E APRECIAÇÃO, que possibilitam o entendimento dos posicionamentos e avaliações dos participantes sobre a profissão docente. 


\section{METODOLOGIA}

Este estudo localiza-se no âmbito da pesquisa qualitativa de cunho interpretativista. Este tipo de tradição investigativa prevê a compreensão das questões com base nos significados que as pessoas atribuem a elas, isto é, um entendimento da realidade sob a ótica dos indivíduos que nela operam.

Para compor o corpus de análise, foram reunidos 20 textos $^{2}$ produzidos por professores de inglês como língua estrangeira que atuam em diferentes contextos e níveis de ensino. Os participantes tinham entre 18 e 50 anos de idade e sua experiência docente com a língua estrangeira variava entre 2 e 25 anos. Os textos foram escritos a partir da seguinte proposta enviada por e-mail ou entregue pessoalmente aos participantes: Cite as características que você considera típicas de um professor (a). Explique de que forma você acredita que se encaixa em tais características.

A partir dos textos, foi iniciada a fase de análise dos dados para esta pesquisa. Realizei manualmente a seleção de trechos dos textos que considerei mais proveitosos para auxiliar no cumprimento dos meus objetivos de pesquisa, isto é, momentos em que fosse possível identificar posicionamentos e avaliações dos professores participantes. Foi considerado o sistema de Atitude do Sistema da Avaliatividade e suas categorias AFETO, JULGAMENTO e APRECIAÇÃO. Nem todos os recursos de análise foram aplicados em todos os trechos observados, uma vez que utilizei as categorias que mais se destacavam em cada fragmento selecionado, tendo em vista o objetivo estipulado inicialmente.

\section{ANÁLISE DE DADOS}

A fim de responder aos objetivos de pesquisa propostos na introdução do artigo, faço uma identificação dos assuntos que apareceram mais recorrentemente nos textos produzidos pelos participantes e que constroem posicionamentos e avaliações sobre a profissão professor. Os referidos assuntos estão divididos em dois eixos temáticos e serão abordados nos itens a seguir por meio da análise de trechos dos textos.

\footnotetext{
${ }^{2}$ Os textos foram reunidos inicialmente para compor o corpus de análise da pesquisa empreendida em Barroso (2009). Na ocasião, foram aplicados procedimentos baseados na Linguística de corpus e na LSF para cumprir os objetivos então propostos (para detalhes, confira Barroso, 2009). Desta maneira, os mesmos dados estão sendo agora utilizados para o estudo dos posicionamentos e avaliações dos participantes sobre sua profissão.
} 


\section{Posicionamentos em relação à profissão: Amor}

Uma questão bastante tematizada na quase totalidade dos textos analisados foi o amor pela profissão sempre funcionando como uma mola propulsora das atividades docentes. Os professores participantes levantam esse tema tanto quando se referem às características que consideram típicas da profissão quanto nos momentos em que se referem ao seu próprio sentimento. No quadro explicativo a seguir, temos, do lado esquerdo, os trechos extraídos dos textos dos participantes. Do lado direito, estão dispostos os comentários sobre as marcações em sublinhado, negrito e itálico nos elementos do texto, o que será detalhado no parágrafo adiante.

\begin{tabular}{|l|l|}
\hline E mais importante que todos estes aspectos, posso & APRECIAÇÃO (Valor) \\
afirmar que não saberia fazer outra coisa na vida que não & $\underline{\text { AFETO }}$ \\
fosse dar aula: amo minha profissão e pretendo ser, a cada & $\underline{\text { AFETO }}$ \\
$\underline{\text { dia, uma professora melhor. }}$ & $\underline{\text { Dentre todas essas características a que faz a diferença }}$ \\
$\begin{array}{l}\text { entre tantos profissionais que estão no mercado, é o amor } \\
\text { pela profissão, é este que nos leva a busca de um }\end{array}$ & $\underline{\text { AFETCIAÇÃO (Valor) }}$ \\
$\begin{array}{l}\text { aperfeiçoamento } \\
\text { características são adquiridas. }\end{array}$ & $\underline{\text { AFETO }}$ \\
\hline
\end{tabular}

Quando analisamos os trechos produzidos pelos participantes, percebemos que toda a sua explanação é permeada de sentimentos emocionais em relação à profissão docente. Isso pode ser identificado de maneira mais clara quando os participantes utilizam palavras diretamente associadas à dimensão AFETO ("amor" e "amo"), construindo um ambiente de maior envolvimento com o tex to e com o assunto tratado.

Somam-se ainda os trechos sublinhados que, juntos, também constroem uma atmosfera mediada pela dimensão afetiva do Sistema da Avaliatividade. No primeiro fragmento, observamos declarações enfáticas sobre a ligação afetiva do participante com sua profissão ("posso afirmar que não saberia fazer outra coisa na vida"). Destacase ainda, em ambos os trechos, declarações de como o amor pela profissão impulsiona a busca por crescimento profissional ("pretendo ser, a cada dia, uma professora melhor" e “é este que nos leva a busca por aperfeiçoamento"). 
Os elementos em negrito remetem à dimensão da APRECIAÇÃO do sistema da Atitude. Os participantes parecem indicar como o amor pela profissão o afetam emocionalmente atribuindo um Valor ou importância social a ele ("mais importante" e "a que faz a diferença”). Como se pode notar, há um posicionamento do professor marcado pelo AFETO em relação à prática docente, evidenciado não só nas palavras individuais como também por outros itens que conferem esse encadeamento para o texto.

Quando se constrói um relato em termos afetivos, o escritor mostra ao leitor como está emocionalmente inclinado em relação ao assunto e o convida a compartilhar consigo os mesmos sentimentos (WHITE, 2001). Além disso, sendo esse AFETO de cunho positivo, pode-se dizer que há uma tentativa de construir o fenômeno que despertou atitudes afetivas (no caso, a profissão docente) como algo benéfico (Ibid.).

De uma maneira um pouco mais intensa, o AFETO se faz presente nos trechos a seguir, que também serão comentados no mesmo modelo já apresentado. Nos casos adiante, os participantes constroem seu posicionamento diante da profissão em termos passionais utilizando recursos do subsistema da Atitude.

\begin{tabular}{|l|l}
\hline Tento mostrar aos meus alunos paixão pelo conteúdo & $\underline{\text { AFETO }}$ \\
ministrado. Por defender que o professor deve ser um & \\
apaixonado pelo que faz, tento, porém não tenho como & $\underline{\text { AFETO }}$ \\
garantir se consigo, mostrar como é importante, & APRECIAÇÃo \\
interessante, envolvente o tópico trabalhado. Para mim, & (Reação e Valor) \\
mostrar-se apaixonado pelo assunto dá crédito ao professor & $\underline{\text { AFETO }}$ \\
e desperta o interesse do aluno (“se ele gosta tanto, deve & $\underline{\text { AFETO }}$ \\
ter algo de especial nisso"). Os professores “apaixonados” & APRECIAÇÃO (Reação) \\
que tive sempre foram os que mais me cativaram. & $\underline{\text { AFETO }}$
\end{tabular}


Uma segunda característica que me move é ser apaixonada pelo que faço. É acreditar que sempre posso fazer algo melhor a cada dia para que as aprendizagens aconteçam, mesmo em ambientes desfavoráveis a elas. Quando digo "algo melhor" quero dizer o "possível", o "palpável”, o “alcançável” e não um esforço desumano para se tentar chegar a algo utópico. A paixão a qual me refiro é algo construído na conscientização dos obstáculos que irei enfrentar, do trabalho, do esforço e do tempo dispensados a um projeto de trabalho. Não é algo doentio.

$\underline{\underline{\text { AFETO }}}$
$\underline{\text { AFETO }}$
APRECIAÇÃOO
APRECIAÇÃO
APRECIAÇÃO/AFETO
$\underline{\text { AFETO }}$

No primeiro trecho do quadro, o professor participante reitera o envolvimento emocional intenso com a profissão por meio de itens lexicais no campo derivacional de da paixão (apaixonado, apaixonados) bem como no campo semântico do amor (gostar, cativar). Ademais, o participante faz uso da APRECIAÇÃO para realizar avaliações positivas sobre a profissão, destacando a Reação que causa ("especial, "interessante", “envolvente") e o Valor que possui ("importante").

No segundo fragmento, temos um texto também marcado pelo AFETO, porém com a paixão dividindo espaço com a razão. Esta dualidade pode ser percebida na declaração da participante de que está engajada afetivamente com sua profissão mesmo diante dos obstáculos ("sempre posso fazer algo melhor a cada dia" e "mesmo em ambientes desfavoráveis"). Além disso, encontramos uma série de recursos de APRECIAÇÃO das condutas na prática docente, que deixam clara sua composição (“possível”, "palpável”, “alcançável” e não "utópico”). A participante, portanto, parece desmitificar um amor incondicional pela profissão, afirmando que não se trata de algo "doentio" e sim um envolvimento afetivo que encontra seus limites na razão do que seria viável realizar dentro da atividade docente.

Este último trecho dialoga e delineia os caminhos para o próximo eixo temático, onde foram selecionados os trechos em que os participantes denunciam os problemas educacionais com os quais se deparam sua prática profissional. 


\section{Avaliações da profissão docente: Desafios}

O conteúdo dos próximos trechos sinaliza os desafios da profissão e as avaliações que os participantes fazem de todo o contexto educacional em que estão inseridos. Inicialmente, proponho a observação de dois fragmentos que seguem.

\begin{tabular}{|l|l|}
\hline $\begin{array}{l}\text { Levando as características da educação brasileira e as } \\
\text { péssimas condições que professores enfrentam para }\end{array}$ & APRECIAÇÃO (Reação) \\
exercer essa função, vale lembrar que é preciso pessoas & AFETO \\
que amem aquilo que fazem e que não escolham a & \\
profissão de educador como aquela mais fácil, e sim & APRECIAÇÃO \\
como aquela mais gratificante. & (Composição e Reação) \\
$\begin{array}{l}\text { Um bom professor ama a sua profissão, apesar de todos } \\
\text { profissão, longas jornadas de trabalho, baixos salários. }\end{array}$ & $\underline{\text { AFETO }}$ \\
$\begin{array}{l}\text { Isto porque, ao final, percebe que o simples fato de ver } \\
\text { que um aluno conseguiu superar uma dificuldade, ou ao }\end{array}$ & AFETO \\
$\begin{array}{l}\text { receber um agradecimento, um sorriso, um abraço por ter } \\
\text { sido uma boa professora, já compensa. }\end{array}$ & \\
\hline
\end{tabular}

Nota-se, no primeiro trecho, que o participante realiza uma APRECIAÇÃO bastante negativa da profissão, utilizando a palavra "enfrentar", relacionada a brigas e guerras, para destacar as condições de trabalho a que estão sujeitos os professores. Em seguida, utiliza a dimensão do AFETO quando afirma a necessidade do amor para lidar com uma conjuntura desfavorável ao profissional. O participante também avalia sua profissão como "não fácil" e "gratificante" através da APRECIAÇÃO de sua composição e reação causada. Para White (2001), o recurso da APRECIAÇÃO desloca o foco do participante para o fenômeno avaliado, que é justamente o que os participantes articulam em seus textos, uma avaliação da profissão tendo em vista suas adversidades e características negativas.

No segundo fragmento do quadro, aponta-se para o trecho inicial destacado em negrito e itálico, onde o participante realiza, ao mesmo tempo, um JULGAMENTO e uma APRECIAÇÃO da profissão docente. Entendo os elementos marcados denotando um JULGAMENTO, na medida em que parecem avaliar um comportamento externo ao 
enunciador e oriundos de uma série de medidas e entidades responsáveis pelas denúncias verificadas no discurso do participante. Ao redor de todas essas avaliações, está o AFETO em relação à profissão, identificado pelo posicionamento perseverante do participante que, a despeito de todas as barreiras, ainda se mostra envolvido emocionalmente com suas atividades. Para Martin \& White (2005) as variáveis JULGAMENTO e APRECIAÇÃO estão normalmente envolvidas pelo AFETO, já que ambos lidam com sentimentos institucionalizados.

A análise desses dados possibilitou o entendimento de que, ainda que em tom de denúncia, os participantes continuam a alicerçar sua prática docente no amor pela profissão, indicando que esse sentimento é uma válvula propulsora de sua opção e permanência no magistério. Os próximos trechos seguidos de suas análises complementam e ilustram o eixo temático discutido.

\begin{tabular}{|l|l|}
\hline $\begin{array}{l}\text { Não é tarefa fácil, especialmente em face de uma } \\
\text { educação sucateada com a qual nos deparamos em nossa }\end{array}$ & $\begin{array}{l}\text { APRECIAÇÃO } \\
\text { (Composição e Reação) }\end{array}$ \\
prática diária e uma desvalorização absurda do professor. & JULGAMENTO \\
mante a mim, tenho tentado, na medida do possível, & JULGAMENTO \\
fatores, como por exemplo, a orientação da própria & \\
instituição de ensino, muitas vezes somos impedidos de & \\
fazer o que acreditamos ser o melhor (...) o professor & \\
finge que ensina e o aluno finge que aprende. & JULGAMENTO \\
\hline $\begin{array}{l}\text { Se fosse listar as características de um professor, faria } \\
\text { uma lista enorme, e talvez, infindável de qualidades que a }\end{array}$ & JULGAMENTO \\
sociedade julga que um bom professor deve ter e que nos & \\
é imposta todos os dias. & \\
\hline
\end{tabular}

Percebemos no primeiro trecho do quadro a APRECIAÇÃO negativa da profissão que não é "fácil" devido ao fato de a educação estar "sucateada", segundo a participante autora do texto. Mais uma vez, notamos o JULGAMENTO da condição desvalorizada da profissão docente que agora foi enfatizada pelo adjetivo "absurda". A participante também faz um JULGAMENTO de seu próprio comportamento diante de um quadro tão negativo, afirmando manter-se fiel aos seus princípios. Podemos inferir 
que há nesse trecho o envolvimento emocional identificado por meio do recurso do AFETO utilizado pela participante quando assegura o respeito às suas crenças não obstante os desafios enfrentados.

Por fim, encontra-se a questão da imposição de práticas e condutas aos professores denunciadas nos últimos trechos em itálico de ambos os fragmentos. Os participantes fazem um JULGAMENTO desse comportamento de impor determinadas formas de ser e agir aos professores, o que contraria, muitas vezes, suas próprias vontades e convicções pessoais.

Segundo White (2001), o JULGAMENTO pode estar direcionado ao comportamento de uma pessoa ou grupo. Sendo assim, acredito que os professores participantes estão fazendo uma avaliação do cenário educacional brasileiro por meio do JULGAMENTO de uma conduta, não individual e sim geral, que desvaloriza o professor. Paralelamente, os participantes desta pesquisa avaliam sua profissão a partir de uma APRECIAÇÃO negativa das condições de trabalho decorrentes dessa conduta.

\section{CONSIDERAÇÕES FINAIS}

O estudo aqui proposto buscou entender o posicionamento e as avaliações do professor de inglês como língua estrangeira sobre sua profissão a partir da análise de seu discurso escrito segundo o viés teórico da LSF e do Sistema de Avaliatividade. O entendimento de linguagem preconizado pela LSF é condizente com esta pesquisa haja vista a análise feita da língua em uso, na qual se leva em consideração os participantes e contexto em que estão inseridos. O Sistema da Avaliatividade auxiliou na análise dos posicionamentos e avaliações presentes no discurso dos professores por meio de seu subsistema da Atitude.

Como entendimentos viabilizados pela análise dos dados, pode-se mencionar a identificação de um posicionamento afetivo dos participantes em relação ao magistério. Esse elo emocional entre docente e profissão funciona como uma motivação que pode se construir de maneira mais ou menos intensa. O vínculo amoroso pode, muitas vezes, compensar uma condição de trabalho penosa e com inúmeros desafios.

Além disso, foram também observadas avaliações dos participantes em relação à profissão, que julgaram negativamente a atual conduta de desvalorização do professor. 
Conjuntamente, os participantes mostraram-se contrários à situação da educação no país apreciando negativamente suas características.

Para a área de estudos da linguagem, este estudo pode colaborar na divulgação de dados em língua portuguesa analisados à luz da LSF e do Sistema de Avaliatividade, panoramas teóricos que contam com a maior parte de sua bibliografia em língua inglesa. A pesquisa também estuda o discurso em contextos pedagógicos no campo da Linguística Aplicada, área fundamental no desenvolvimento de uma agenda política para a pesquisa científica. Nesse sentido, como contribuição dos entendimentos aqui disponibilizados está a possibilidade de acesso aos posicionamentos e avaliações de professores que vivenciam a prática docente construídos em/pelos seus discursos. Ouvir essas pessoas, suas experiências e impressões talvez seja uma maneira de direcionar possíveis mudanças em um contexto aparentemente fragilizado.

\section{REFERÊNCIAS BIBLIOGRÁFICAS}

ALLWRIGHT, D. \& BAILEY, K. (1991). The development of classroom research. Why focus on the classroom? In: Focus on the language classroom: An Introduction to Classroom Research for Language Teachers, 2-17; 18-33. Cambridge: Cambridge University Press.

BAKHTIN, M. (1988a). Marxismo e filosofia da linguagem. São Paulo: Hucitec.

BAKHTIN, M. (1992). Estética da criação verbal. São Paulo: Martins Fontes.

BARBARA, L. \& MACEDO, C. M. (2009). Linguística Sistêmico-Funcional para a análise de discurso um panorama introdutório. Cadernos de Linguagem e Sociedade, vol. 10(1), 89-107.

BARROSO, S. C. (2009). Tematização e Representação da prática docente: análise sistêmico-funcional da construção discursiva da profissão e da identidade do professor de inglês como língua estrangeira. Dissertação de Mestrado. Rio de janeiro: PUC-Rio.

BUTT et al. (1998). Using Functional Grammmar: An Explorer's Guide. Sydney: Macquarie University.

CAVALCANTI, M. C. (2004). Applied Linguistics: Brazilian perspectives. Aila Review, 17, 23-30.

CHAPELLE, C. A. (1998). Some notes on Systemic-Functional linguistics. Disponível em: http://www.public.iastate.edu/ carolc/LING511/sfl.html. Acesso em: 15 set 2012. 
CUNHA, M. A. F. \& SOUZA, M. M. (2007). Transitividade e seus contextos de uso. Rio de Janeiro: Lucerna.

DIRECT (PUC-SP) et. al. Termos da gramática sistêmico-funcional em português aprovados para utilização pelos participantes da lista de discussão gsfemportugues@egroups.com. Disponível em: http://ww3.fl.ul.pt/pessoais/cgouveia/ docs\%5CTermosGSF.pdf. Acesso em: 10 set. 2012.

EGGINS, S. (2004). An Introduction to systemic functional linguistics. London: Continuum.

GOUVEIA, C. A. M. (2009). Texto e gramática: uma introdução à Linguística Sistêmico-Funcional. Matraga, v.16, n.24, 13-47.

GIROUX, H. A. (1997). Os professores como intelectuais: rumo a uma pedagogia crítica da aprendizagem. Porto Alegre: Artes Médicas.

HALLIDAY, M. A. K. (1976). Estrutura e função da linguagem. In: LYONS, J. (org.). Novos horizontes em linguística, 134-160. São Paulo: Cultrix.

HALLIDAY, M. A. K. \& HASAN, R. (1989). Language, context, and text: aspects of language in a social-semiotic perspective. Oxford: Oxford University Press.

HALLIDAY, M. A. K. (1994). An Introduction to Functional Grammar. London: Arnold.

HALLIDAY, M. A. K. \& MATTHIESSEN, C. (2004). An Introduction to Functional Grammar. London: Arnold.

LINCOLN, Y. S. \& DENZIN, N. K. (2006). O sétimo momento: deixando o passado para trás. In: DENZIN, N. K. \& LINCOLN, Y. S. (orgs.). O planejamento da pesquisa qualitativa, 389-406. Porto Alegre: Artmed.

MARTIN, J. R. (2001). Beyond Exchange: APPRAISAL Systems in English. In: HOUSTON, S. \& THOMPSON, G. (eds.). Evaluation in Text, 142-175. Oxford: Oxford University Press.

MARTIN, J. R. \& WHITE, P. R. R. (2005). The language of evaluation: appraisal in English. New York: Palgrave Macmillan.

MERCER, N. (1994). Neo-Vygostkian Theory and Classroom Education. In: STIERER, B \& MAYBIN, J. (eds). Language, Literacy and Learning in Educational Practice, 92-110. Clevedon: Multilingual Matters.

MOITA LOPES, L.P. (2003). Socioconstrucionismo: Discurso e identidades Sociais. In: MOITA LOPES, L.P. (org). Discurso de Identidades, 13-38. Campinas: Mercado de Letras. 
MOITA LOPES, L. P. (2006). Por uma Lingüística Aplicada Indisciplinar. São Paulo: Parábola Editorial.

MOITA LOPES, L. P. (2009) Linguística Aplicada como lugar de construir verdades contingentes: sexualidades, ética e política. Revista Gragoatá, vol. 27, 33-50.

NEVES, M. H. M. (1997). A Gramática Funcional. São Paulo: Martins Fontes.

PENNYCOOK, A. (2006). Uma lingüística aplicada transgressiva. In: MOITA LOPES, L. P. (org.). Por uma Lingüística Aplicada Indisciplinar, 67-84. São Paulo: Parábola Editorial.

SCHLEE, M. B. F. (2011). Breve abordagem da categoria discursiva modalidade. Revista da Academia Brasileira de Filologia, Nova Fase, n. IX, segundo semestre, 157169.

STUBBS, M. (1992). Whys is Language Important in Education? The Need for Classroom Studies. Studies of Classroom Language. In: Language, Schools and Classrooms: Contemporary Sociology of the School, 15-23; 88-117.

THOMPSON, G. (1996). Introducing Functional Grammar. London: Arnold.

VYGOTSKY, L. S. (1999). Pensamento e Linguagem. São Paulo: Martins Fontes.

WELLS, G. (1994a). The Complementary Contributions of Halliday and Vygotsky to a "Language-Based Theory of Learning". Linguistics and Education, 6, 41-90.

WELLS, G. (1999). Language and Education: Reconceptualizing Education as a dialog. Annual Review of Applied Linguistics, 19, 135-155.

WHITE, J. (2001). Appraisal: an overview. Disponível em www.grammatics.com. Acesso em: 20 out 2012.

\section{A AUTORA}

Suzana de Carvalho Barroso Azevedo possui Graduação em Letras (PortuguêsInglês) pela Universidade Federal do Rio de Janeiro (UFRJ) e Especialização em Ensino de Inglês pela Universidade Federal de Minas Gerais (UFMG). Cursou Mestrado em Estudos da Linguagem na Pontifícia Universidade Católica do Rio de Janeiro (PUCRio), onde atualmente é doutoranda em Estudos da Linguagem. Atua como professora de língua inglesa há 12 anos e faz parte do quadro permanente do CEFET/RJ, campus Nova Friburgo, como professora de língua inglesa e portuguesa.

\section{E-mail: susanabarroso@gmail.com}

